\title{
UNLOCKING THE IMPACT OF COVID 19 ON ASSAM SILK INDUSTRY: CHALLENGES AND STRATEGIES TO REVIVE THE INDUSTRY
}

\author{
Ms. Dimpal Bharali \\ Dr. Sunildro LS Akoijam
}

\section{Abstract}

The purpose of this paper is to explore the challenges faced by different stakeholders of Assam Silk industry due to COVID 19 pandemic. Moreover the paper identifies strategies to revive the silk industry. The study is qualitative and data were collected through in-depth interview from weavers, manufacturers as well as raw and finished silk products suppliers using semi structured questionnaire. The findings indicate that all the stakeholders are affected very badly by the pandemic. The paper will act as a framework or guidelines to policy makers to frame policies and to stakeholders in formulating strategies to revive the industry.

Keywords: Covid-19 pandemic, impact, Assam silk industry, suppliers, sustainability.

\section{Introduction}

The COVID 19 was originated and first reported in Wuhan city of China in December 2019 which later on declared as pandemic by World Health Organisation (WHO). As on August 2, 2020, more than 7.7 million cases have been reported across 188 countries (Wikipedia) According to the International Monetary Fund (IMF), the global economy is expected to shrink by over 3 per cent in 2020-the steepest slowdown since the Great Depression of the 1930s. The IMF's estimate of the global economy growth at $-3 \%$ in 2020 is an outcome "far worse" than the 2009 global financial crisis. Advanced economies have been hit harder and together they are expected to grow by $-6 \%$ in 2020 . Emerging and developing countries are expected to contract by $-1 \%$.

In India, the first case of the COVID 19 was reported on 30th January 2020. India currently has the largest number of confirmed cases in Asia and the third largest number in the world after 
Towards Excellence: An Indexed, Refereed \& Peer Reviewed Journal of Higher Education / Ms. Dimple Bharali \& Dr. Sunildro Akoijam / Page 69-81

USA and Brazil (worldometers). As on 2nd August 2020, India has crossed the mark of 16 lakhs confirmed case and surging to cross 17 lakhs confirmed cases in a couple of days (Arogya setu app). Since the confirmation of COVID 19 case in India, the economy started shrinking due to the fear psychosis generated in the minds of people across the industry. But the dramatic downfall in the economy started when the Prime Minister of India, Shri Narendra Modi announced for nationwide lockdown Phase 1 from 24thMarch 2020 for a period of 21 days due to the immense spike in the number of confirmed cases of COVID 19 across the country. Even before the completion of 1 st nationwide lockdown, on the advisory of various state governments, the government of India extended the lockdown further in phase 2 (15th April to 3rd May 2020) followed by phase 3 (4th May to 17th May 2020) and phase 4 (18th May to 31st May 2020).

It was during this nationwide lockdown for almost 3 months, the economy collapsed with complete closure of almost all industries except few which falls under essential commodities. It resulted in increase in unemployment, decreased in Government income, consumer activity reduced, problems in supply chains, plunge in fuel consumption and rise in liquefied petroleum gas (L.P.G.). It directly hit the industries like Automobile, Aviation, Tourism \& Hospitability, Real estates, Agriculture, Micro, Small \& Medium Enterprises, and education sector. The world where we live always changes with time and situation. To cope up with various changes we need to bring new possibility in reality to broaden the greater horizon. Lockdown has created many new business models, and successfully popularizing the various use of technology by a finger click. Customer buying behavior \& purchasing power and market needs, demand \& supply has completely changed the marketing strategies. So the marketers have to be dynamic \& proactive in delivery to meet the needs and requirements of consumers easily accessible at the doorstep.

The silk industry of Assam also witnessed a serious downfall during the lockdown.COVID-19 Lockdown has put strict restrictions by completely shutting all shops, institutes, organizations and vehicular movement except emergency services. It has made people stay indoors by banning social gathering, and limiting celebration at home .Very few wedding occurred and festivals like Bihu which takes place in mid of April could not be celebrated and other religious ceremonies are limited to indoors the sale of Assam silk sale as declined directly during after 
lockdown. Silk is categorized as a luxury product not as an essential necessity, so the sale of Assam silk products has declined during and after lockdown. The bread earners associated with Assam silk faced difficulty in their survival. The weavers or manufacturers could not sell their finished products as there are no customers for buying. The finished silk products are stocked and after some day's raw materials scarcity aroused making problem for weavers. The weavers are out of their job and male weavers started finding job for their meal as daily wage earners at construction sites or other available jobs after lockdown. The silk yarns prices hike causing problem for the manufacturer's raw materials purchases. The finished silk suppliers faced different types of problem to run their business after lockdown as this year the wedding and Bihu sales were disrupted. This paper attempts to examine the impact of COVID-19 pandemic on Assam silk industry by exploring the problems faced by the weavers, manufacturers, raw silk material suppliers and finished silk suppliers. It also attempts to identify new strategic moves to unlock the challenges by discovering silk potentialities.

\section{Review of Literature}

Covid-19 pandemic has shattered the micro, medium and small industries so subsidy on utilities like on water ,electricity to manufacturing enterprises require, financial institute to continue loan moratorium for at least 6 months more and Government can provide interest subvention on loans to MSME's by Mudra loan to recover the global pandemic crisis suggested by Micro save Consulting in Annual report of June 2020.Bansal,Sharma and Gautam (2020) discussed that lockdown will impact negatively in the economy of India in commercial, service, manufacturing activities and social life. Tax will fall, deficit of Indian GDP, unemployment rise and supply of essential goods will suffer. Kumar, Thombare \& Kale (2020) revealed corona virus epidemic estimated impact in India will be 348 million dollars affecting in industries like chemical industry, poultry, agriculture, auto industry, electronic industry and in foreign trade. Shafi, Liu and Ren (2020) found in their research COVID-19 outbreak and lockdowns in Pakistan has affected MSME's severely by financial losses, supply chain disruption, demand decrease of products, sales and profit reduction. Agrawal, Jamwal and Gupta (2020) found in their research that Covid -19 outbreak has affected not only US and Europe, it has affected the supply chain of developing countries like India to choke or shut down assembly lines temporarily. Sukhesh Madaan, an entrepreneur, on April 22, 2020 wrote 
Towards Excellence: An Indexed, Refereed \& Peer Reviewed Journal of Higher Education / Ms. Dimple Bharali \& Dr. Sunildro Akoijam / Page 69-81

in his article about Reserve Bank of India's moratorium on term loans, putting off on interest payment, relieve working capital financing. Public sector banks introduced emergency credit for MSME borrowers to avail 200 crore loan or $10 \%$ of the existing fund based working capital limits. $5 \%$ rate concession for MSME loan takers. GST payment dates extended to June 2020. The Economic Times, April 29, 2020 publishes that as per Tea Association of India (TAI) complete lockdown has hit the tea industry hardly at the time of beginning the season after manufacture.

\section{Assam Silk Industry}

Assam occupies a significant place worldwide for its golden color Muga silk, warm Eri silk and white or off white Mulberry silk. The silk industry of Assam was mentioned in Kautilya's Arthashastra, of $3^{\text {rd }}$ century B.C., and in other ancient mythology \&scriptures like Ramayana, Mahabharata and Harshacharita. The silk industry of Assam has been a source of livelihood for entire North East India since decades. The Assam silk production is mainly for sale locally \& nationally and exports internationally. Assam is the leading state in the country in terms of handloom weaving and natural silk production. Assam is worldwide popular since ancient times in production and manufacturing of high quality silk products. Assam produces Muga silk, Mulberry silk \& Eri silk, which are weaved by the skilled artisans of Sualkuchi, the silk weaving cluster of Assam. According to Sualkuchi Handloom Survey 2016, there are 10398 active handlooms in Sualkuchi silk weaving cluster and 3452 weavers, 198 helpers,1278 manufacturers ,190 silk traders having own shops all over Assam and 80 raw silk suppliers. There are 6312 Mulberry (Pat) silk handlooms,110 Muga silk handlooms,2304 Tasar silk handlooms, 06 Eri silk handlooms and 1666 non silk handlooms. In Assam, no ceremonies, festivals, wedding and any other special occasions are possible without wearing pious silk products manufactured in Sualkuchi cluster. Silk items are preferred to be sacred and offered to God and Goddesses' .The sale of Assam silk is maximum in the wedding seasons, festivals like Bihu, Pujas and other ceremonies.

\section{SWOT analysis of Assam silk industry}




\section{a) Strengths}

1) Indigenous \& age old traditional industry having varieties of basic skills. It is a source of livelihood \& contributes to national income.

2) Assam mulberry silk and Muga silk are pride of Assam .It shows the culture of Assam. Assam's Muga silk enjoys global monopoly and it is a GI (Geographical indication) tag product.

3) Availability of artistic and cheap well trained \& skilled weavers.

4) Presence of favorable environment like soil, rainfall which is helpful in the growth of Som \&Sualu tress where silkworms are feed

5) Demand of Assam silk and Muga products globally. The raw silk, readymade silk fabrics and special handloom fabrics have International demand.

\section{b) Weakness}

1) Assam sillk and Muga fabrics are hand woven with little use of machinery so it becomes time consuming.

2) In spite of large pool of skilled and technically qualified manpower having diplomas, certificates and degrees of varieties of Textile institutes, college and fashion institutes, the Assam silk market is not explored to a great extent. They are not using their skills as they lack in fund and fear to take risk.

3) Lack of use of new technology in marketing and sales.

4) Assam silk fabrics are expensive while Muga fabrics are very expensive.

5) Outdated and minimal use of machinery in this handloom industry.

6) Assam silk industry is unorganized .Presence of unregulated and unorganized market.

7) There are too many unregistered exploitative middlemen in the marketing channel. 
Towards Excellence: An Indexed, Refereed \& Peer Reviewed Journal of Higher Education / Ms. Dimple Bharali \& Dr. Sunildro Akoijam / Page 69-81

8) Assam silk producers and manufactures lack financial help from Government and other financial institutions. They don't have direct access to customers so the producers and manufacturers earning less profit

9) Assam silk is gradually diminishing, as the new generation is not attracted to this industry.

10) Lack of Assam silk advertisement and promotional activities. This industry is surviving by word of mouth publicity and generation to generation use of silk products in festivals and religious occasions.

11) No government interventions in market entry of cheap, low quality and similar imported silk products.

12) Similar silk like products with same design \& eye appealing colorful machine finished and low quality competitive substitutes availability in the market at cheap price.

13) The looms are mainly hand woven in Assam silk industry of Sualkuchi so it takes time in producing the fabric and it becomes difficult to achieve economies of scale.

14) With increasing substitutes to Assam silk industry, the sellers find difficulty in selling the high quality pure silk products at competitive prices to its customers.

15) Till now, the production level is not up to the world standards in terms of supply, technological uses in sales and marketing, infrastructure, labor laws and management deficiencies.

16) The new generation is not attracted to this industry so the handlooms are reducing day by day due to shortage of weavers.

\section{c) Opportunities}

1) There are plenty of opportunities for innovative designer wears and customized designer fabrics to make different attires to meet the demands of domestic and foreign customers.

2) Exploring foreign markets as there is huge demand in international market for raw silk and silk fabrics \& ready-mades which require graded bivoltine (producing two broods in one year) silk. 
3) Climate of Assam is favorable for natural rearing of silkworms.

4)Assam silk fabric production need to be increased as there is too much demand for natural silk worldwide .So, product diversification is the need of the hour, as foreign customers want natural Assam silk fabrics in their own attires.

5) There are plenty of opportunities to set up large or niche silk mills for producing Assam silk and Muga silk and blended fabrics to meet customer's demand.

6) Branding of Assam silk globally, though there is huge demand for silk but absence of direct distribution channel. As there is a huge traditional domestic demand for silk requiring multivoltine (producing several broods in one year) silk.

7) Availability of large pool of skilled and technically trained manpower coming from the various Textile institutes, colleges and fashion institutes.

8) It generates huge employment generation by using silk blended and knitted designer customized wear.

9) Introduction of internet portals for selling silk products.

\section{d) Threats}

1) Tough competition from cheap imported, low quality yarns and power loom products.

2) Traders sell finished silk products made of cheap quality similar to silk in the name \& price of genuine Assam silk.

3) Global warming, natural calamities like flood and change of natural climate is becoming unsuitable for silkworms farming. It effects on silk production.

4) Market dominance and huge profit bearer are the large scale traders, middlemen and the sellers in the marketing channel. Silk producers and manufacturers could not earn more as they rely on middlemen for selling their products. 
5) Mobility of skilled weavers to their own place and start the same business in their homes. This skilled weaver use unskilled and untrained weavers at cheap rate to maintain his business and deteriorates the quality standards of the products.

6) Government not setting barriers in the entry of low quality, cheap, similar to silk products from outside.

7) Government have no rules and policies to punish the traders selling duplicate and low quality ,cheap silk products in the name of Assam silk.

\section{Research Methodology}

The study is qualitative. The data were collected by using semi structured questionnaire through in-depth interview method from weavers, manufacturers, raw silk material suppliers and finished silk product suppliers (20 each) in different parts of Assam. Secondary data has been taken from webinars, symposium expert's lectures, reports, official websites, Government circulars, available articles in newspapers and WebPages \& other offline \&online published research papers. The data found are analyzed in theme wise in narrative and descriptive way.

\section{Problems faced by stakeholders of Assam Silk industry due to COVID 19}

\section{Problems faced by the raw silk material suppliers}

1) The movement of goods was stopped.

2) Entire supply chain of silk is affected.

3) The silk yarn price falls due to lack of demand.

4) Distribution channel disturbed badly as there arises labor problem due to containment zones in many places, so the truck drivers found difficulty in loading goods. So, the raw silk materials are not delivered on time.

5) Transportation problem, during lockdown only essential commodities were allowed to move and silk is a luxury item not basic essential goods for survival. 


\section{Problems faced by the manufacturers of Assam silk}

1) Finished silk products are stocked in home as many orders were cancelled and no new orders placed by the buyers.

2) Instant rise of silk yarn prices during lockdown created problem in shortage of fund by the manufacturers to purchase raw silk yarns at high prices.

3) No new bulk orders of silk products as many occasions and ceremonies were postponed and strict restrictions on social gathering.

\section{Problems faced by the weavers of Assam silk}

1) The weavers were out of job, they were weaving up till the manufacturers had silk yarns in stock. The handlooms were closed due to unavailability \& high price of raw silk yarns.

2) As many orders were cancelled and no new orders were placed so the weavers had no assignments. The earlier stocks were not sold so manufacturers have no liquid cash in hand finding problem in paying the weavers full amount of wages.

3) The weavers had to search other jobs for their daily meal. The male weavers started working in construction sites on daily wage basis to earn daily meals.

Problems faced by the finished silk products suppliers (distributors, wholesalers and retailers) of Assam silk

1) All silk shops or outlets were closed and restricted to open on certain days and timings so offline business faced interruptions. The online orders faced delay in delivery due to certain places lockdown.

2) Foreign orders were cancelled and no new order placed locally, nationally and internationally storing huge stocks in home and in stores.

3) COVID -19 pandemic has spoiled the wedding and Bihu season sale so it aroused fund shortage to run their business. The finished silk products suppliers faced problem in salary payment to its employees, pay electricity bills and shops rent etc. 


\section{Strategies to revive the Assam Silk Industry during and after COVID 19 Pandemic}

Considering the challenges faced by various stakeholders of Assam Silk industry during COVID -19, the paper identifies the possible strategic moves to minimise the losses and revive the industry during and after lockdown. Looking through the lens of SWOT analysis and interview findings, the various proposed strategies can be called for action to recover the production cost and revive \& sustain the silk industry of Assam. Lockdown has created many new business models, and successfully popularised the various use of technology by a finger click. Customer buying behavior, purchasing power, market needs, demand \& supply has completely changed the marketing strategies. So the marketers have to be dynamic \& proactive in delivery to meet the needs and requirements of consumers easily accessible at the doorstep. Assam silk finished products need to be offered discount to clear the stock and recover production cost by the manufacturers and finished silk products suppliers' social media pages and in stores. Assured free gifts with new orders of Assam silk fabrics can be implemented to pay wages to the weavers. Now a day's all Smartphone users have social media accounts and applications like Facebook, Instagram, What's app, Telegram, Hike etc. The suppliers can showcase their finished products with pictures and provide the provision for 'call for order' and deliver products safely contactless at home offering discount. Designing silk masks and promoting benefits of Assam silk like it is natural, non allergic, skin friendly, long time usable, washable, very small particles can enter though silk can be highlighted. Branding and exporting Eri silk, Muga silk, Mulberry silk mask is the need of the hour by tying up with major online retailers like Amazon, Flipkart, Health kart etc. Assam silk products can be advertised in news channels and in popular regional \& national newspapers about stock clearance discount. Manufacturers can also participate in NEDFI's and other Government promotions agencies online exhibitions. Promotional campaigns by branding benefits of silk uses nationally and internationally. Manufacturers should be offered short term courses on making project plan, make uniform high quality standard products and attractive packaging to avail government schemes and exporting silk products.

Immediate help can be offered by state Government to help the weavers to get daily wages by delivering subsidized raw silk yarns home to home or in Gram Panchayat centres. The manufacturers and raw silk suppliers facing problems in purchasing raw materials due to late 
delivery and transportation problem. Government can build, strengthen the distribution channel and provide relaxation to silk goods movers vehicles to reach in time. Government should extend support to ensure bulk availability of raw silk materials on subsidized rate. Accessing Government financial assistance schemes like mudra loan and Atmanirbhar Bharat etc to expand silk product lines will be beneficial. Government of Assam can organize cluster development program to train \& teach latest internet technology to silk manufacturers of Sualkuchi silk weaving clusters to promote and market silk products online. These proposed strategies can relieve the pandemic survival crisis of weavers, wholesalers \& retail shopkeepers, and raw materials suppliers of Assam silk. This findings and discussions will be of immense benefits to weavers, wholesalers \& retail shopkeepers, and raw materials suppliers of Assam silk.

\section{Conclusion}

COVID -19 pandemic has hit silk industry of Assam to a great extent. These study findings explored the impact of COVID-19 pandemic on Assam silk industry and identifying the possible strategic moves to balance the losses incurred during and after lockdown. COVID -19 pandemic has hit silk industry of Assam to a great extent. The stakeholders need to look forward to cover the losses by using online marketing platforms to reach the target customers. Silk Industry of Assam is the backbone of earning foreign exchange and source of livelihood for the people of North East India. To recover and sustain the silk industry of Assam, immediate Government financial assistance and raw silk materials supply to weavers \& manufacturers at subsided rate is required. The industry needs to strengthen its marketing strategies particularly promotion, branding and aggressive selling of unsold finished products with discounts. The industry also needs to use the online platform for promoting and selling their products with assurance of delivery of products safety during the pandemic and lockdown. Manufacturers and finished silk products suppliers can expand new product lines in silk to meet the crisis. Research and development of silk is the need of the hour to make new usable products highlighting health benefits. 
Towards Excellence: An Indexed, Refereed \& Peer Reviewed Journal of Higher Education / Ms. Dimple Bharali \& Dr. Sunildro Akoijam / Page 69-81

References

Agrawal, S., Jamwal, A., and Gupta, S. "Effect of COVID-19 on the Indian Economy and Supply Chain." Preprints 2020, 2020050148 (doi: 10.20944/preprints202005.0148.v1).

Baker, S. R., Farrokhnia, R. A., Meyer, S., Pagel, M., and Yannelis, C. How does household spending respond to an epidemic? Consumption during the 2020 covid-19 pandemic NBER Working papers (No. w26949). National Bureau of Economic Research 2020.

Bansal, C. N. K., Sharma, S., and Gautam, A. A Study on Impact of COVID-19 a Global Pandemic on Indian

Chetia, S. The Assames Handloom and Textile Tradition, Parbotia, Tinsukia: The Assam Computers, 2000

Emmaneil, R. "A profile of handloom industry in India." Journal of Exclusive Management Science 1.7 (2012): 14-27.

Kumar, S., Thombare, P. B., and Kale, A. P. "Impact of coronavirus (COVID-19) on Indian economy." Agriculture and Food: e-News letter 2.4 (2020): 301-302.

Mukherji, A. and Verma, N. Socio-economic backwardness in women, New Delhi: Ashish Publishing House, 1987.

Patel, U. "Role of Handloom Industry in India." International Indexed \& Referred Research Journal 4.39 (2012): 1-2.

Serdihun "13TH Annual Conference.", Souvenir, All Assam Handloom and Textile Officer's Association, 2009

Shafi, M., Liu, J., and Ren, W. "Impact of COVID-19 Pandemic on Micro, Small, and MediumSized Enterprises operating in Pakistan." Research in Globalization 2 (2020): 2-15.

Shah, M. U. "Problems and Development of Cooperative Development." Kurukshetra, 11.5 (1998):11. 
Singh, N. K. "Promotion and Development of Handloom Sector." Souvenir, National Handloom Expo"99 ARTFED 1997.

\section{Ms. Dimpal Bharali}

Research Scholar, Department of Management, North Eastern Hill University, Tura Campus, Tura, Meghalaya $\&$

\section{Dr. Sunildro LS Akoijam}

Assistant Professor, Department of Management, North Eastern Hill University, Tura Campus, Tura, Meghalaya

Email-sunil.mba.amity@gmail.com; drsunildroakoijam@gmail.com) 